\title{
Does the ideal entrepreneurial team exist?
}

\author{
Patricia Fuel $^{1} \cdot$ Manuela Pardo-del-Val $^{2}$ (D) $\cdot$ Lorenzo Revuelto-Taboada $^{2}$ (D)
}

Accepted: 29 December 2020 /Published online: 8 February 2021

(c) The Author(s), under exclusive licence to Springer Science+Business Media, LLC part of Springer Nature 2021

\begin{abstract}
Up until now, studies on entrepreneurs and their relationship to business performance have focused primarily on analyzing the entrepreneur as an individual. While studies have been conducted on the entrepreneurial team, their focus has centered on team size and degree of diversity - cultural, age, gender - leaving a gap in the analysis of the effect of a team's competencies on the outcome of the ventures. This research aims to help fill this gap by using the psychometric instrument DISC. This research analyzes entrepreneurship by opportunity, evaluating the performance of 109 Colombian companies and the composition of their entrepreneurial teams. The results obtained provide the basis for better understanding of the make-up of entrepreneurial teams, considering the variances and interdependencies of the competency development level among their members. They reveal that identifying the similarity or heterogeneity in certain groups of competencies, as well as how developed they are, can have an impact on the ventures' success. The cluster analysis carried out suggests that highly developed competencies associated with the 'dominance' dimension in the members of an entrepreneurial team are essential. These must be above-average in heterogeneous levels among the team members. They must also be accompanied by the 'steadiness' competency provided by the teamoriented partners, as well as an average, homogeneous level of competencies associated with 'conscientiousness' if the new business is to achieve good financial results in its early years. The 'influence' dimension did not play a significant role. The teams made up of more homogeneous partners obtained the poorest financial results. Furthermore, the study provides new perspectives for measuring business performance in a venture, as well as for evaluating the relationships between the entrepreneurial team's competencies and the company's results in the first years of business. Accordingly, it offers inputs for future research.
\end{abstract}

Keywords Entrepreneurial teams · Entrepreneurial competencies $\cdot$ DISC $\cdot$ New firms' performance

Extended author information available on the last page of the article 


\section{Introduction}

The recent COVID-19 pandemic has had devastating effects on the business community in many countries around the world. According to the World Bank, the economic recession is the worst since World War II. Governments of all political orientations are striving to design measures that will jumpstart economic recovery. These include providing ways to generate income for the unemployed, as just one of the instruments that need to be implemented immediately. Given the number of companies that are going or have gone bankrupt and are in a fragile financial situation, entrepreneurship will be an option for many workers who will not be able to recover their jobs in the short or medium term. Some entrepreneurs will choose to start afresh, after being forced to put their companies into liquidation after a long period of lockdown without being able to open for business even partially for many weeks and even months.

At this moment in time, when resources are scarce and new companies need to be created, both by new entrepreneurs and by entrepreneurs who are trying again, tools are needed to increase the probability of success of this new business community. It is worth noting the high business mortality rates that occur in the first years of a company's history (Aldrich and Auster 1986; Brüderl and Schüssler 1990; Churchill 1955; Freeman et al. 1983; Levinthal 1991), with the first year being the riskiest in terms of survival (Brüderl et al. 1992; Fernández et al. 2018) according to data from the Spanish National Statistics Institute (INE 2016). If we combine these indicators with the current environment of uncertainty in international markets, the volatility of macroeconomic variables and the complexity generated by global interdependence, business mortality rates may well increase.

Despite the extensive literature on business management analyzing the elements that trigger entrepreneurship, the personal characteristics of entrepreneurs and their relationship with business results, theory on the subject is still limited and further research is needed to explore the relationship between business behavior and performance (Kirkley 2016; Kollmann et al. 2017).

Several studies have focused on analyzing the skills of an entrepreneurial individual (Brandstätter 1997; Di Zhang and Bruning 2011; Eser and Özdemirci 2016; Fernández et al. 2018; Littunen 2000; Marulanda et al. 2014). However, there is still no scientific consensus on a specific profile. In addition, new ventures are increasingly set up by several partners, so the creation of a working team is relevant as it generates a combination of competencies that can affect business performance. Nevertheless, there is still neither enough literature nor applied analysis about this topic or about the issue of whether there is an ideal composition for an entrepreneurial team.

This leads to the identification of a gap in how to manage new companies, given that not being aware of the impact that the combination of different team member competencies can have leads to wasting opportunities, missing potential openings and to entrepreneurial teams being created without sufficient awareness of how they can improve their collective performance. The situation is exacerbated when team members simultaneously perform several roles (entrepreneur, 
investor, operator and manager) in the company, with the characteristics and behaviors that each of these roles implies, given that the mix of roles and functions can be contradictory in some aspects and complementary in others (Cuervo et al. 2007).

The sum of the sparse literature available, the increase in the creation of new companies, the literature gap about putting together entrepreneurial teams and the configuration of their collective competencies brings us to the following research question: Is there a combination of competencies in an entrepreneurial team that contributes significantly to improving business performance? Based on this question, this paper seeks to provide insights from a socioeconomic perspective as to why entrepreneurial teams have different business outcomes in apparently similar competitive environments.

In this sense, the objective of our research is to broaden the understanding of the competency mix of entrepreneurs who join forces as a team to start up a new company, as well as the team's direct and indirect influence (Tehseen et al. 2019) on the company's performance in its early years of business. Three specific objectives emerge from this general goal. The first is to analyze and develop the applicability of a measurement instrument to identify the competency profiles required in the composition of an entrepreneurial team. The second objective is to determine a tool to measure business performance in newly created companies. Finally, the third objective is to analyze typical entrepreneurial teams based on their competency profiles and the results of their companies.

First of all, this article sets out a theoretical review which defines the term 'competency' and then moves on to address the concept of an entrepreneurial team and how its competencies and performance can be measured in a new company. Next, an empirical study of entrepreneurial teams is presented, starting with the methodology and followed by a description of the sample and of the subsequent clusters that emerge from our analysis. After a discussion of the results, the paper ends by highlighting the academic and business implications of our study, as well as its limitations and suggestions for future lines of research.

\section{Theoretical framework}

\section{Competency}

Since McClelland first referred to the concept of competency in 1973, it has become popular and its importance is widely recognized in literature. However, in practice there is considerable confusion as to what it really means, the dimensions it covers, its classifications and its application to carry out a task or to perform better in the work environment (Chen and Chang 2010; Delamare and Winterton 2005; Hafeez and Essmail 2007).

In the English language there are two similar concepts, but with different meanings: competence and competency. Literature often shows conflicting definitions of these two concepts, and although their exact difference is not definitive (Hoffmann 1998; Weightman 1994), competence or competences, refers to the minimum 
capacity to perform a job, while competency or competencies, is related to people's behavior and how this varies and improves their performance (Chen and Chang 2010; Hafeez and Essmail 2007).

Without attempting to go beyond what is strictly necessary in defining the concept of competencies, this study shares the perspective of Hartle (1995) and considers that competency is 'a characteristic of an individual that has been shown to drive superior job performance' (1995, p. 107), and includes both the visible 'competencies' of 'knowledge' and 'skills' and 'underlying elements of competencies', as well as 'traits and motives'.

In short, for this study and when forming entrepreneurial teams, competency is a multidimensional construct, a combination of personality characteristics, skills, abilities, attitudes and behaviors, including motivations and values, which effectively lead to superior performance in a new enterprise (Hartle 1995; McClelland 1976; RezaeiZadeh et al. 2017; White 1959).

\section{The entrepreneurial team and its competencies}

Though it is true that there is much individual entrepreneurship, it is increasingly common to set up businesses in teams; in fact, Neumeyer and Santos (2020) stated that companies founded by teams grow more than those founded by individual entrepreneurs.

The formation of an entrepreneurial team can generate advantages by synergizing skills, knowledge and resources (among other aspects), while increasing the likelihood of different opinions on specific issues, and differing strategic views and personal interests when it comes to distributing expenses and returns. Conversely, this diversity can lead to an increase in conflict, which requires coordination and negotiation over time to be able to act as a team not as a group (Backes-Gellner et al. 2015).

An entrepreneurial team "consists of two or more persons who have an interest, both financial and otherwise, in and commitment to a venture's future and success; whose work is interdependent in the pursuit of common goals and venture success; who are accountable to the entrepreneurial team and for the venture; who are considered to be at the executive level with executive responsibility in the early phases of the venture, including founding and pre- start up; and who are seen as a social entity by themselves and by others" (Schjoedt and Kraus 2009: 515). Accordingly, they join forces to start up a company in which they are partners, employees and management team members. In line with the definition of teamwork (Brandstätter 1997), an entrepreneurial team has to meet two criteria: ownership in the company and responsibility for its performance.

Recent research has paid attention to the composition of the founding teams of new companies (Clarysse and Moray 2004; Cooney 2005; Zhou et al. 2015; Zolin et al. 2011), analyzing variables such as size (Backes-Gellner et al. 2015), cultural diversity, age, profession and gender (Buyl et al. 2011). Nevertheless, a gap remains in the study of the appropriate combination of ideal team competencies, even though work with lists of the best competencies at individual level is frequent, despite the 
growing trend towards teamwork (Chen and Chang 2010; Delamare and Winterton 2005; Hafeez and Essmail 2007).

The success factors of a venture center on resources, opportunity and people. For example, a key element in identifying the early chances of success of fast-growing technology-based companies is people with their competencies, their ability to run the business, and how they manage to build a winning team in which there may be competency combinations among the founding partners that are more likely to succeed than others (Timmons et al. 2004). In this sense, Khalil and Khalil (2020) indicated that innovative companies are characterized by a combination of various key competencies within a single team.

The selection processes for team-led projects to receive subsidies, funding, awards, business accompaniment in incubators, accelerators or seed and risk capital are quite subjective in different countries. It is usual in Europe and the Americas, where there is greater progress in both the study and the implementation of programs to promote entrepreneurship (Baier-Fuentes et al. 2019), to determine the best talent in a broad group of new ventures, setting up a committee of experts or juries in the style of a "shark tank", who are then asked to subjectively select the ventures that deserve the award.

When evaluating the entrepreneurial team, which should be one of the most important assessment criteria, the training, experience and technical knowledge of its members are considered. However, there is a lack of elements of judgment that transcend the 'feeling' about evaluating which team is well formed to work together in starting up a company and consolidating it. The tools for technical evaluation (such as those used with the business plan or model) of team suitability and identification of those that are more likely to succeed are precarious and not widespread.

Unger et al. (2011) reviewed the literature on the relationship between human capital and success over a thirty-year period and found that "although a positive relationship between human capital variables and success is well established, uncertainty remains over the magnitude of this relationship as well as the circumstances under which human capital is more or less strongly associated with success. To date, the literature remains fragmented with studies differing in the conceptualization of human capital, the choice of success indicators, and the study contexts such as industry, country, and age of the business" (Unger et al. 2011, p. 341).

By considering how competencies are combined in an entrepreneurial team, we can analyze whether the composition of entrepreneurial teams has any effect on different business outcomes in similar competitive environments. Furthermore, this enables us to reflect on whether there is a combination of team competencies that contributes to business success, thus broadening the understanding of the combination of team competencies in a new company and their influence on the venture's performance.

\section{DISC as a measuring instrument}

Configuring team competencies is based on the individual sets of competencies its members have. These competencies are the result of a combination of knowledge 
and experience, but they are only acquired if certain personality traits are present. Personality thus becomes the foundation on which the development of competencies is based (Levy-Leboyer 1997).

This research analyzed different alternatives to study and measure personality, temperament and approach to competencies, such as E-Scan (Driessen and Zwart 1999), Team Balance Index (Ten Haaf et al. 2002), Big Five or Five Factor Model FFM (John et al. 1991), 16PF (Cattell 1946; Cattell et al. 1993), Enneagram (Wagner 1981), Myers-Briggs Type Indicator (MBTI) (Myers 1962), Keirsey Temperament Classifier (Keirsey and Bates 1984), and BSOK (Altink and Born 1993). Finally, following Ciavarella et al. (2004) and Berglund and Wennberg (2006), the DISC instrument was chosen (Forsyth et al. 2016; Sugerman 2009), because it is the one that most closely resembles the measurement of competencies that transcends mere personality traits (Chen et al. 2016; Eser and Özdemirci 2016; Ferneda et al. 2012), and because it is used in various institutions dedicated to the promotion of entrepreneurship.

DISC, an acronym for Dominance, Influence, Steadiness and Conscientiousness, uses the Behavior Analysis Questionnaire based on the work of Dr. William Moulton Marston, who in his 1928 book Emotions of Normal People introduced the theory behind this instrument. From the model proposed by Marston, John G. Geier developed a system for psychometric analysis of the social working climate, also often used as a tool for consultancy. This system, known as DISC Management, has become one of the most common procedures for the selection and management of staff in the business world and in academic environments (Pérez Fernández 2010).

The foundations of DISC establish that each individual has a unique combination of competencies that are grouped into DISC categories or dimensions. The competency behavior style for each DISC category can be summarized as follows (CIC 2015; Forsyth et al. 2016; Persolog 2007; Sugerman 2009):

- Dominance, dimension D. Independent, direct people who are not afraid to be forceful. People with this style are results-oriented and push to keep things moving. They are people with a strong character who enjoy challenges, action and immediate results.

- Influence, dimension I. Cheerful, outgoing people who love to be surrounded by more people; their enthusiasm is evident. They are talkative and appreciate the opportunity to work with others. They are optimistic and prefer to participate in teams, share thoughts, be fun and energize others.

- Steadiness, dimension S. People who constantly show their concern for others, and are ready to serve. They look for stable, predictable environments, and want everyone to get along. They enjoy working in a team and lend themselves to being supportive of others. They tend to participate from behind the scenes and work consistently and predictably; they are good listeners.

- Conscientiousness, dimension C. Analytical people who care about precision. They always concentrate on obtaining quality work, dedicate time to it and usually create and inhabit formal atmospheres, where they concentrate more on the rational than on the emotional. They are very interested in the fine details, because they believe they are the key to obtaining quality results. 
For the interests of this study, DISC reports a combination between personality and competencies. That is, it ties together two of the most important categories that are tracked in studies measuring personal factors in entrepreneurs. This instrument explores individual priorities and how those priorities influence behavior. Fig. 1 illustrates and summarizes the DISC model, its four dimensions and the competencies that are associated with each dimension.

The DISC instrument employs a method known as ipsative testing, that is, using forced scores. It uses a neutral language, implying that there are no right or wrong styles of behavior. The questionnaire has a set of options, each consisting of four adjectives, which ask the test taker to identify which is more applicable to him or her. The underlying structure of the DISC is multidimensional in nature and is composed of four subscales. Each represents a separate but correlated dimension of behavior style.

Rodriguez (2004) analyzed the DISC tool mathematically and statistically, showing that the internal structure of the test is constant for all countries, as is the bipolar nature of the dimensions of the model, showing the reliability and scientific validity of DISC as a methodology for assessing competencies in people. Agencies like Thomas International also provide data on the validity of construct and criterion validity, so it is considered that the DISC model meets the standards of psychometric quality required for such tests. DISC has also been subjected to Flesch-Kincaid's test of comprehensibility and Flesch's test of readability (Inscape Publishing 1997).

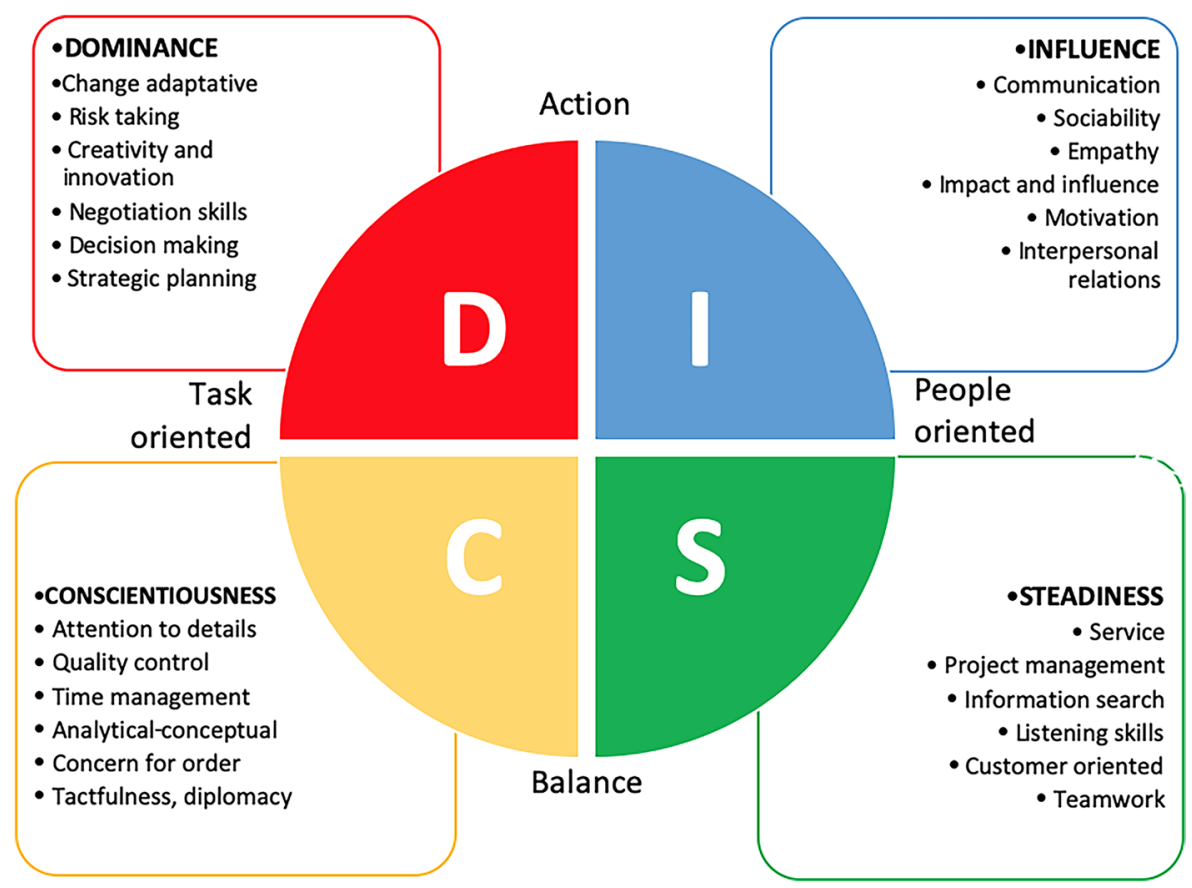

Fig. 1 DISC model with competencies grouped in each dimension. Source: Adapted from Inscape Publishing (2005) and TIMS International 
Other evidence of the DISC methodology's reliability and validity includes the Cronbach Alpha coefficient to assess the internal consistency of the four subscales and the full scale; McNemar's non-parametric test to relate two variables to the dichotomous result; the Kappa coefficient and the DISC structural factor accessing the use of two specific types of analytical factor: the Q-technique, and the R-technique marked within a structural equation model, using modifications of the ipsative scores. The results presented in all statistical tests indicate that DISC's psychometric properties are consistent and reliable (Inscape Publishing 2005).

\section{Measuring performance in entrepreneurial ventures}

After selecting the psychometric instrument for measuring the competencies of the entrepreneurial team, we now focus on defining business performance for new companies. This measurement is significantly different for that of consolidated companies.

Business performance is one of the most important multidimensional constructs in management research and, therefore, it is understandable that it has been studied from different perspectives. In spite of this, there is no consensus regarding the method of measuring performance in a recently created company (Bayarçelika and Özşahinb 2014; Omerzel and Kušce 2013; Ripollés and Blesa 2005). Murphy et al. (1996) reviewed how entrepreneurial performance was measured in the entrepreneurship literature between 1987-1993 and found that more than $60 \%$ of the studies used only one or two dimensions of performance, usually without giving much rationale to their selection.

Pérez and Canino (2009) reviewed the literature to understand the measures applicable to the performance of a new venture. They found that quite a few researchers considered it dangerous to limit the evaluation of the potential progress of a new company to one or two financial indicators, because the scarce historical information and the instability of the first years of a newly created firm do not allow for suitable analysis. Some researchers even considered mere survival to be a factor in assessing a company's success.

A large number of proposals for measuring the performance of a new company (Brown and Caylor 2004; Cooper and Artz 1995; Davidsson and Honig 2003; Nicholls-Nixon et al. 2000; Morris 2011; Omar et al. 2014; Pérez and Canino 2009; Reijonen and Komppula 2007; Stam et al. 2014; Wiklund 2009), argue that a multidimensional approach is essential. Omerzel and Kušce (2013) outlined these dimensions, suggesting that entrepreneurship should be evaluated based on the achievement of goals and objectives, both in terms of business results and in terms of the perception of personal performance and satisfaction of the entrepreneurial team itself.

Previous research has suggested using the Balanced Scorecard method (Kaplan and Norton 1992) to measure performance in entrepreneurial ventures and small firms (Gumbus and Lussier 2006). This tool offers a good starting point to design a multidimensional approach as it focuses on key perspectives that tackle the main performance-related issues. It is suitable because it was developed as a complement 
to assess financial performance by balancing short- and long-term objectives through four perspectives that provide a comprehensive description of businesses. Unfortunately, as was the case for Lopes and Farinha (2018), neither the traditional Balanced Scorecard, nor its updates are fully suited to our measurement purposes. Therefore, this research proposes an adapted model that will be presented in the methodological section.

\section{Methodology}

The present study has an exploratory, correlational and explanatory nature, with a transversal approach, in which it was not possible to define specific hypotheses. This was because there are no precedents in the literature to hypothesize an ideal entrepreneurial team profile with defined competencies and desirable levels of variance for each set of competencies which could be associated with better organizational performance by evaluating them with DISC.

The quantitative analysis of the impact of the entrepreneurial team's competencies in the performance of newly created companies was addressed by measuring the entrepreneurial teams' competencies and the performance of the enterprises under study.

\section{Instrument for measuring the competency profile and business performance}

To measure the profile of the entrepreneurs who were part of the teams and the results of their ventures, an online questionnaire was designed and pre-tested in eight cases. The questionnaire had three sections. The first one collected contact data, socio-demographic profile, satisfaction, motivation, perception of aptitudes and the competencies of the entrepreneurial teams' members. The second section included a scale of analysis of the DISC model's behavior. The last section of the questionnaire requested information aimed at responding to the perspectives of measuring business performance with quantitative and qualitative variables. Not all of the variables collected were used in this report. However, they were kept and could be used as inputs for future research.

The DISC was used to analyze the combination of competencies of the entrepreneurial teams' members and the extent to which these complemented each other. Both the range of variation in the levels of each group of skills, as well as the overall degree of competencies were considered when interpreting the results.

Since the tools used to measure performance in consolidated companies could not be applied to the measurement of entrepreneurial ventures, a measurement instrument was designed using the more general classification model proposed by Kaplan and Norton (1992) as a reference. This contemplated financial (some of which were completed using the ORBIS database) and non-financial indicators, as well as objective and subjective measures that make up the multidimensional construct of entrepreneurial performance. The results obtained during the first two years of the 
companies' trading were taken into consideration, analyzing the performance within the framework of the six perspectives that are shown in Table 1.

\section{Sample settings}

The units of analysis were companies less than 11 years old and their entrepreneurial teams. The entrepreneurial team was understood to be a group of at least two people who are founders, owners and are responsible for the performance of the company. It should be noted that the sample was taken from opportunity-based entrepreneurships, supported by different programs in Colombia. Although companies are set up in the country's main cities, such as Bogota, Cartagena and Manizales, most of the entrepreneurial teams are accompanied by the entrepreneurial ecosystem in Medellin and its metropolitan area. Medellin was recognized as the most innovative city in the world in the 2012 competition promoted by Citigroup and The Wall Street Journal, beating New York and Tel Aviv.

The data time frame was the first two years of business for the sampled companies. The strategy to promote entrepreneurship in Colombia dates back to the 1990s, when the initial legislation that boosted development and support for small and medium enterprises began to emerge, reaching its peak in 2006 with the creation of the Law to Promote a Culture of Entrepreneurship (Colombian Congress 2006). From that moment on, an industry to support entrepreneurship began to emerge in the different states aimed at implementing favorable environmental conditions to facilitate and promote the creation of companies in Colombia.

Major difficulties were encountered when setting up a comprehensive up-to-date database with a sufficient number of cases to be analyzed. This was due to the lack of information available in the entrepreneurship promotion agencies, the need to discard a large number of sole traders and the reluctance of companies to provide the necessary information. Finally, a database was created with 109 companies (valid cases) and 245 entrepreneurs who were members of these firms' entrepreneurial teams. It should be noted that more than a hundred ventures were discarded due to a profound lack of information about the company or the entrepreneurs.

\section{Description of the sample}

The sample was grouped by defining three major economic sector categories: Industry, Services and ICT (Information and Communication Technologies), represented by $31.28 \%, 52.48 \%$ and $26.24 \%$ of the companies, respectively. $81 \%$ of the firms had two partners, $15 \%$ had three and the rest had four or more. $67 \%$ of the entrepreneurs were men. It is worth noting that no significant differences in business performance were identified based on these variables. The set of entrepreneurs showed values in the DISC dimensions that are reflected in Table 2.

Once these data and the frequency graphs of the four dimensions and independent variables had been analyzed, we were able to affirm that the distributions were close to normal and that the quality of the sample was sufficient to continue to process the data. 


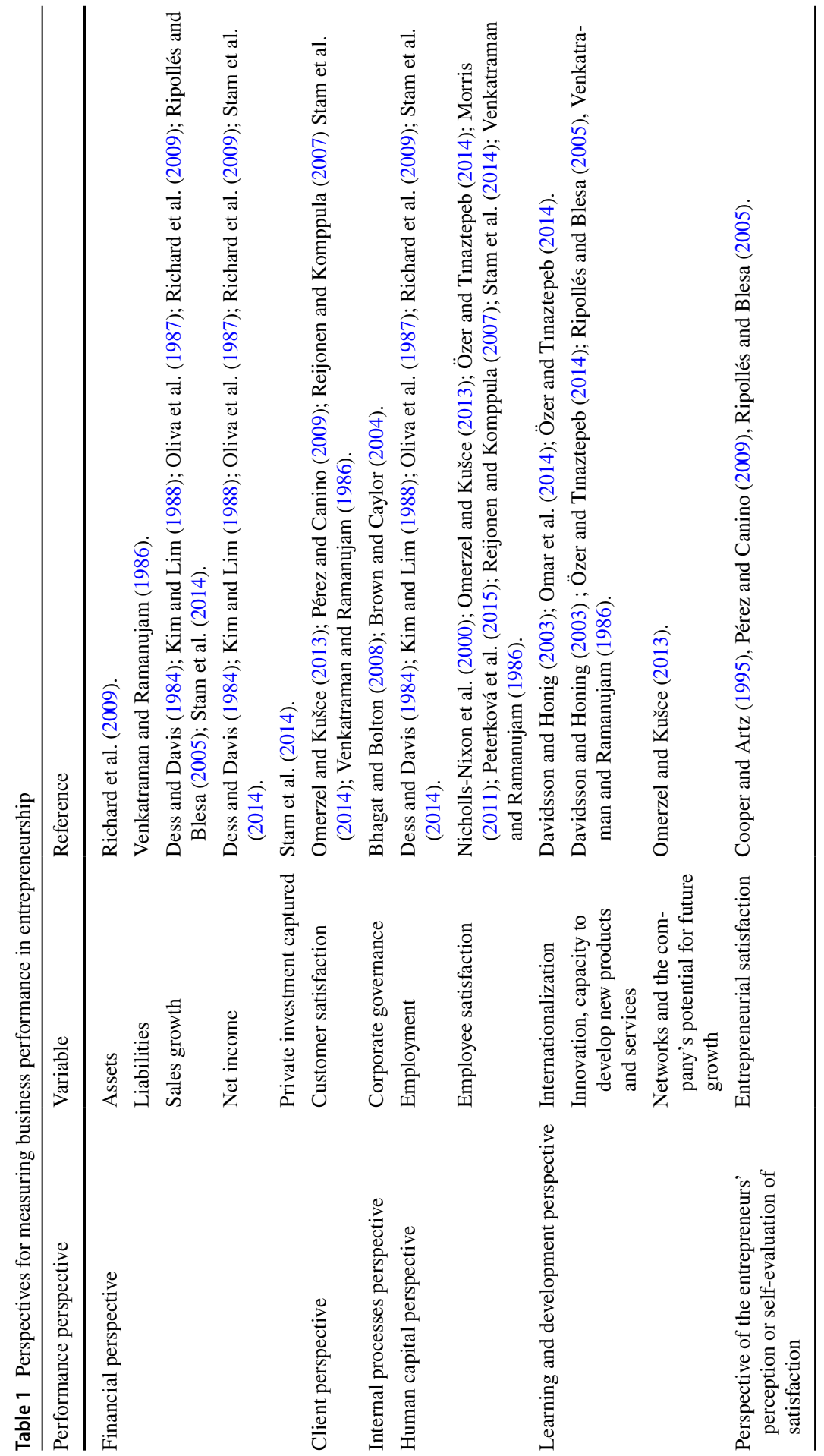


Table 2 Descriptive statistics by DISC dimension

\begin{tabular}{lcccc}
\hline & D & I & S & C \\
\hline Mean & 54.22 & 49.79 & 44.91 & 52.19 \\
Median & 52.78 & 47.22 & 44.44 & 52.78 \\
Mode & 50.00 & 55.56 & 50.00 & 50.00 \\
Standard deviation & 18.10 & 18.63 & 14.85 & 18.05 \\
Sample variance & 327.65 & 346.93 & 220.50 & 325.78 \\
C.V. & $33.38 \%$ & $37.41 \%$ & $33.06 \%$ & $34.59 \%$ \\
Kurtosis & -0.59 & -0.58 & -0.12 & -0.37 \\
Asymmetry & 0.05 & 0.26 & 0.12 & -0.06 \\
Minimum & 11.11 & 8.33 & 8.33 & 8.33 \\
Maximum & 97.22 & 93.00 & 92.00 & 97.22 \\
\hline
\end{tabular}

N.B.: the score in each dimension goes from 0 to 100

\section{Analysis techniques applied}

A hierarchical cluster analysis, Ward's hierarchical method, was applied to the standard deviations of the DISC dimensions. Since each person has a unique DISC combination, a team of entrepreneurs will have a degree of dispersion in the four DISC dimensions which, it should be remembered, combine competencies related to each of the four styles of behavior. In studies of team heterogeneity, standard deviations are often used to measure data at team level and to understand diversity between members. This measure of dispersion provides an understanding of the range of team member competencies (Ensley et al. 1998), which contributes to the scarce research on the diversity of competencies among members of an entrepreneurial team (Kollmann et al. 2017).

A visual inspection of the dendrogram was used to determine the number of groups. Prior to the application of the cluster analysis it was found that there were no problems of multicollinearity between the classification variables and, considering that the number of variables used was small, it was not deemed necessary to carry out a previous factorial analysis.

In order to verify how the identified groups differed, we carried out an ANOVA, which showed the classification variables in which there were significant variations between the groups, as well as post hoc tests to determine which groups specifically differed from each other. In the variables for which the assumption of homogeneity of variances was fulfilled, we used the F test results, and the Tukey test for the post-hoc comparisons. Where the assumption of homogeneity of variances could not be made, we used the results obtained with the Brown-Forsythe statistic instead of the F test, and the Games-Howell test for post-hoc comparisons.

This procedure was applied again to analyze the metric performance variables, in order to ascertain whether membership of the group and, therefore, a specific combination of competency profiles of the group's members, affected the results obtained. Additionally, in the case of non-metric and qualitative performance variables, contingency tables were used and the values of the Pearson Chi-square independence 
test were observed to confirm convergences and to analyze the differences in performance between the different groups.

\section{Results}

The main characteristics of the sample allowed us to move on and identify a number of groups by cluster analysis.

\section{Identification and characterization of clusters}

Figure 2 shows the dendrogram that graphically displays the results of the cluster analysis. The visual inspection of this dendrogram shows how a solution made up of three clusters was reached relatively soon, with a large "jump" to directly reach the solution of a single cluster. Cluster 1 had 55 companies, Cluster 2 had 41 and the remaining 13 were part of cluster 3 .

The ANOVA results showed that there were significant differences (Sig. $=0.000)$ in all the standard deviations considered. The post-hoc analysis (see Table 3) shows that significant differences in the classification variables were found in $75 \%$ of the pair group comparisons ( $\mathrm{sig}$. $=0.000)$.

Significant differences were reported for the variable D deviation in cluster 3 compared to the others. In the case of deviations I and $\mathrm{C}$, there was a difference between cluster 1 and the other two. For the $\mathrm{S}$ deviation, all clusters were different from each other.

An analysis of the diagrams shown in Figs. 3, 4 and 5 reveal the main characteristics of the three clusters as follows:

Cluster 1 was the largest group of the three identified in this study. It shows a greater heterogeneity in the DISC scores of the team members in the Influence and Conscientiousness dimensions. This distribution of I suggests that someone will take care of the relationships, working environment and communication, ensuring decisions continue to be made and important tasks are not left undone. Cluster 1 is unique because the upper levels of Dominance and Conscientiousness are similar, although they differ in dispersion. Being at similar levels could lead to difficulties when making decisions, by combining almost the same level of determination with caution in terms of risk-taking, care and meticulous analysis. However, it may also be the optimal combination of determination with appropriate risk analysis, rapid

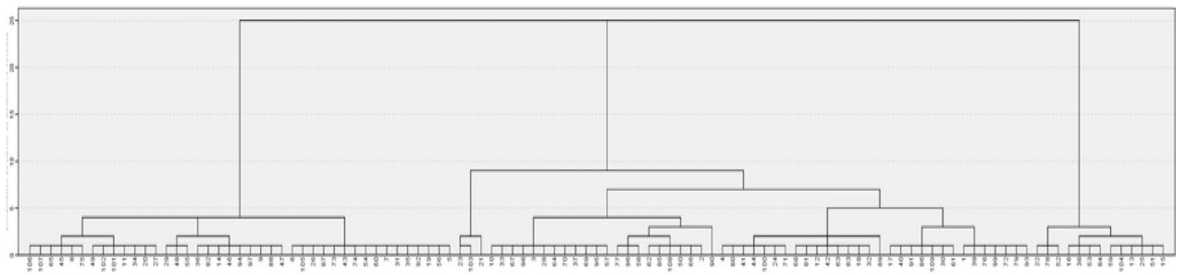

Fig. 2 Dendrogram 
Table 3 Multiple comparisons for the difference between deviations

\begin{tabular}{|c|c|c|c|c|c|c|c|c|}
\hline \multirow{2}{*}{\multicolumn{2}{|c|}{$\begin{array}{l}\text { Dependent vari- } \\
\text { able }\end{array}$}} & \multirow{2}{*}{$\begin{array}{l}\text { (I) } \\
\text { CLU3_1 }\end{array}$} & \multirow{2}{*}{$\begin{array}{l}\text { (J) } \\
\text { CLU3_1 }\end{array}$} & \multirow{2}{*}{$\begin{array}{l}\text { Average } \\
\text { difference } \\
(\mathrm{I}-\mathrm{J})\end{array}$} & \multirow{2}{*}{$\begin{array}{l}\text { Standard } \\
\text { error }\end{array}$} & \multirow[t]{2}{*}{ Sig. } & \multicolumn{2}{|c|}{$95 \%$ confidence interval } \\
\hline & & & & & & & $\begin{array}{l}\text { Lower } \\
\text { limit }\end{array}$ & Upper limit \\
\hline \multirow[t]{6}{*}{ DesvD } & Post Hoc & 1 & 2 & 2.922 & 1.529 & 0.140 & -0.71 & 6.56 \\
\hline & & & 3 & $-18.350^{*}$ & 2.285 & 0.000 & -23.78 & -12.92 \\
\hline & & 2 & 1 & -2.922 & 1.529 & 0.140 & -6.56 & 0.71 \\
\hline & & & 3 & $-21.272^{*}$ & 2.358 & 0.000 & -26.88 & -15.67 \\
\hline & & 3 & 1 & $18.350^{*}$ & 2.285 & 0.000 & 12.92 & 23.78 \\
\hline & & & 2 & $21.272^{*}$ & 2.358 & 0.000 & 15.67 & 26.88 \\
\hline \multirow[t]{6}{*}{ DesvI } & Post Hoc & 1 & 2 & $11.162^{*}$ & 1.606 & 0.000 & 7.34 & 14.98 \\
\hline & & & 3 & $10.997^{*}$ & 2.401 & 0.000 & 5.29 & 16.70 \\
\hline & & 2 & 1 & $-11.162^{*}$ & 1.606 & 0.000 & -14.98 & -7.34 \\
\hline & & & 3 & -0.165 & 2.478 & 0.998 & -6.06 & 5.73 \\
\hline & & 3 & 1 & $-10.997^{*}$ & 2.401 & 0.000 & -16.70 & -5.29 \\
\hline & & & 2 & 0.165 & 2.478 & 0.998 & -5.73 & 6.06 \\
\hline \multirow[t]{6}{*}{ DesvS } & Post Hoc & 1 & 2 & $7.102^{*}$ & 1.315 & 0.000 & 3.97 & 10.23 \\
\hline & & & 3 & $-12.808^{*}$ & 1.966 & 0.000 & -17.48 & -8.14 \\
\hline & & 2 & 1 & $-7.102^{*}$ & 1.315 & 0.000 & -10.23 & -3.97 \\
\hline & & & 3 & $-19.910^{*}$ & 2.029 & 0.000 & -24.73 & -15.09 \\
\hline & & 3 & 1 & $12.808^{*}$ & 1.966 & 0.000 & 8.14 & 17.48 \\
\hline & & & 2 & $19.910^{*}$ & 2.029 & 0.000 & 15.09 & 24.73 \\
\hline \multirow[t]{6}{*}{ DesvC } & Post Hoc & 1 & 2 & $11.891^{*}$ & 1.360 & 0.000 & 8.66 & 15.12 \\
\hline & & & 3 & $12.049^{*}$ & 2.033 & 0.000 & 7.22 & 16.88 \\
\hline & & 2 & 1 & $-11.891^{*}$ & 1.360 & 0.000 & -15.12 & -8.66 \\
\hline & & & 3 & 0.158 & 2.098 & 0.997 & -4.83 & 5.15 \\
\hline & & 3 & 1 & $-12.049^{*}$ & 2.033 & 0.000 & -16.88 & -7.22 \\
\hline & & & 2 & -0.158 & 2.098 & 0.997 & -5.15 & 4.83 \\
\hline
\end{tabular}

risk management, and timely decision-making. The previous graph shows average Steadiness levels and this was the dimension with the highest concentration of scores in the four dimensions. This means that the partners in this cluster are more similar to each other in this set of competencies (patient, discreet, reliable, calm, good listeners, stability, service) than in other sets or dimensions. This group could be called the "Certain Calculators" or "Cautiously Risky".

Cluster 2 was the second largest group and shows low dispersion among the entrepreneurial partners in the four dimensions. Three of the four dimensions (D, I, C) were very even and very close to the average, while presenting the lowest level in the S dimension, compared to the other two clusters, which could lead to more leisurely teamwork dynamics and slower speeds in project management. It could be said that there is less pressure to obtain results than in cluster 1, that the partners do not excel in any of the dimensions and are very similar to each other. We could call this group the "Homogeneously Balanced". 


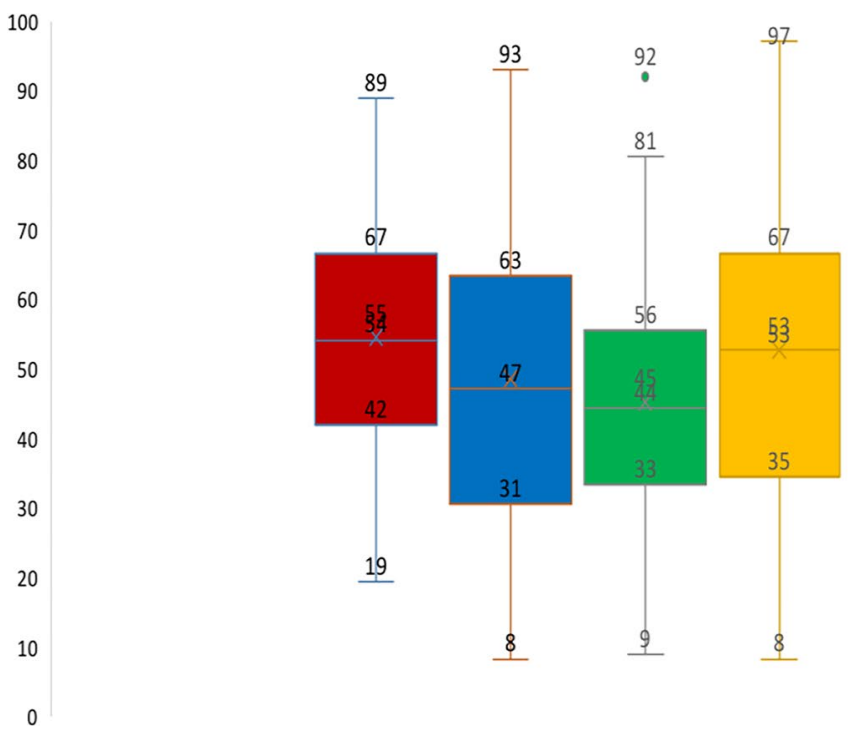

Fig. 3 Box and whisker graph or clustered boxplot 1

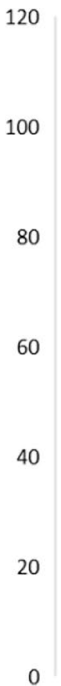

Fig. 4 Box and whisker graph or clustered boxplot 2

Cluster 3 was the smallest of the three. The most remarkable characteristic is that it presents a Dominance dimension with high maximum values and very high dispersion. A high $\mathrm{D}$ dimension is associated with prominent orientation to results, a taste for establishing goals, making decisions to tackle problems and solving them in a timely manner. The members are highly different in this set of 


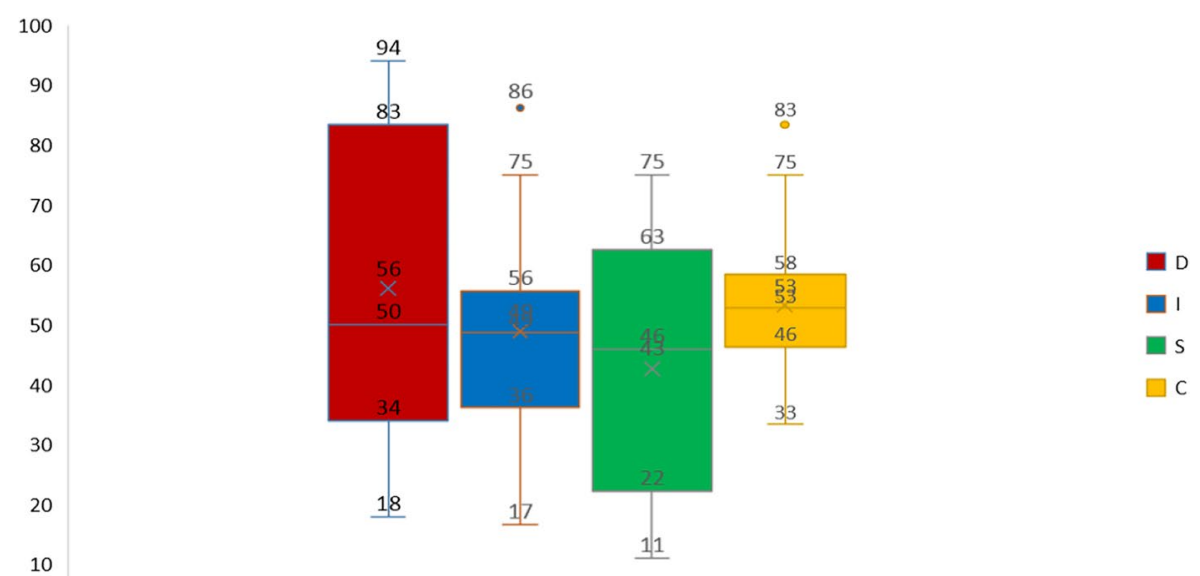

Fig. 5 Box and whisker graph or clustered boxplot 3

competencies. A priori, this seems positive because if the levels of D were high and homogeneous, the team could end up competing against each other and this could generate conflict. In the case of the Steadiness S variable, high dispersion was also detected though with slightly lower maximum values. The combination of some partners with high $\mathrm{D}$ and others with high $\mathrm{S}$ could be complementary, facilitating a balance between pursuing the result and seeking harmony in the process. On the other hand, minimal diversity is observed in dimension $\mathrm{C}$, which is highly concentrated around the average. There is also low dispersion in dimension I. This indicates that the members of the entrepreneurial teams are very similar in the levels of control, attention to detail, quality and thoroughness, as well as in looking after relationships, the working environment and communication, although their levels are lower than the other two groups. We could call this group: the "Dispersed Determinants".

According to the description of each cluster in terms of the DISC dimensions based on the deviations, differences can be graphically observed for each group, establishing profiles for the entrepreneurial teams with different levels of diversity among their members in each of the dimensions.

\section{Organizational performance by cluster}

Although more variables were analyzed to measure entrepreneurial performance, the present analysis focuses exclusively on the variables in which significant differences were detected between the different clusters. No significant differences in results were found in the first year, but they did appear in the second year. Figs. 6, 7 and 8 show the differences in financial results across clusters to facilitate the comparison of results. 


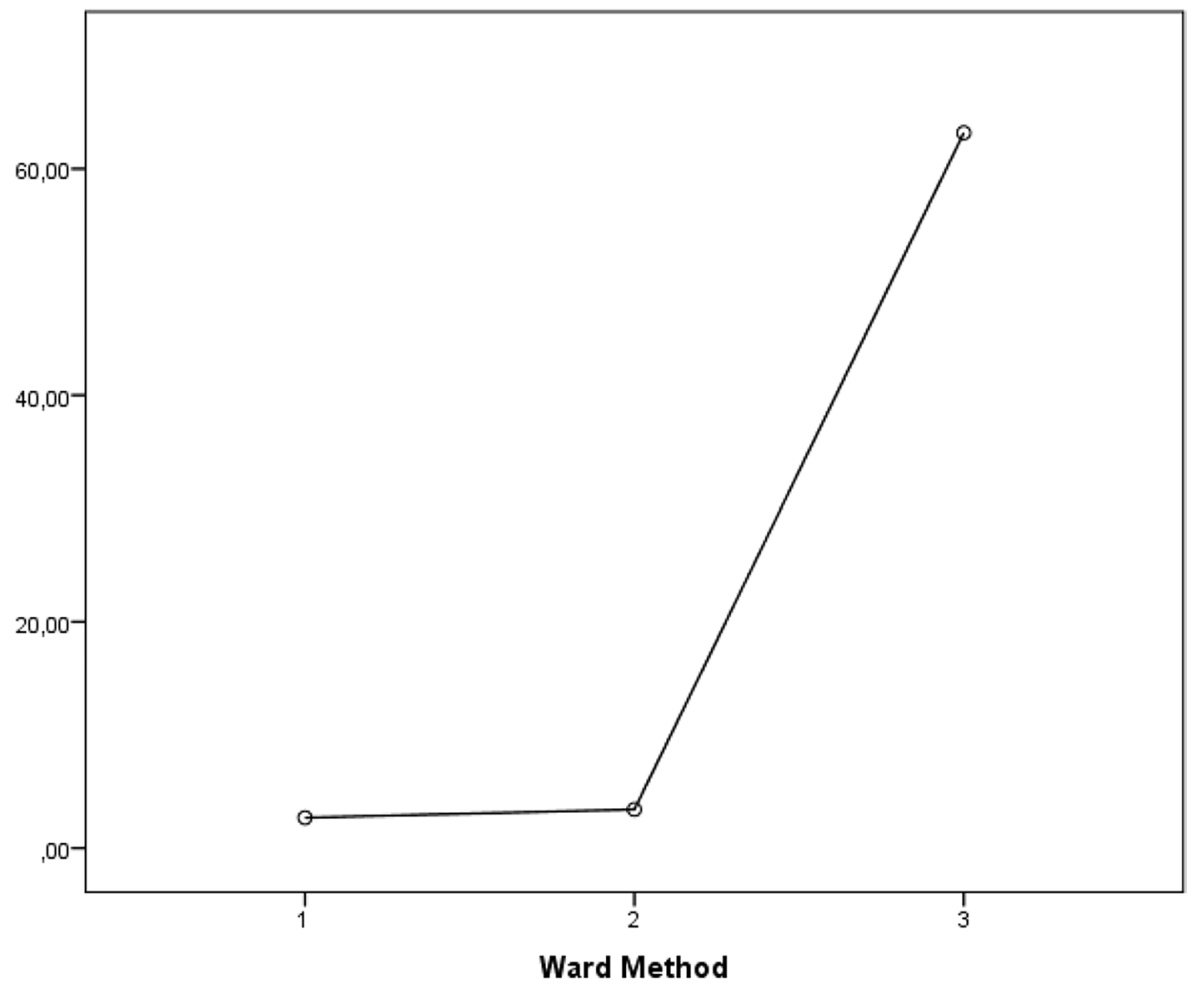

Fig. 6 Average for asset turnover in year 2 for each cluster

\section{Cluster 1}

In the second year of business, as shown in Figs. 7 and 8, the ROE and ROA variables in this group show the second-best business results, though these are a long way behind the success of the "Dispersed Determinants". Regarding Asset Turnover (Fig. 6), this cluster is very similar to the "Homogeneously Balanced" group in cluster 2 , though both have much lower performance compared to cluster 3 .

In terms of the behavior of the qualitative variables analyzed, this group had the highest proportion of companies that received resources from investors.

This cluster stands out as being the most committed to "innovation" as a differentiating factor for success. Its second priority to achieve success is "quality" and it does not consider the "price" factor at all when attempting to differentiate itself from the competition.

Another of the qualitative variables analyzed was the capacity to develop business networks. This shows that approximately half of this cluster's companies were associated with some type of network. 


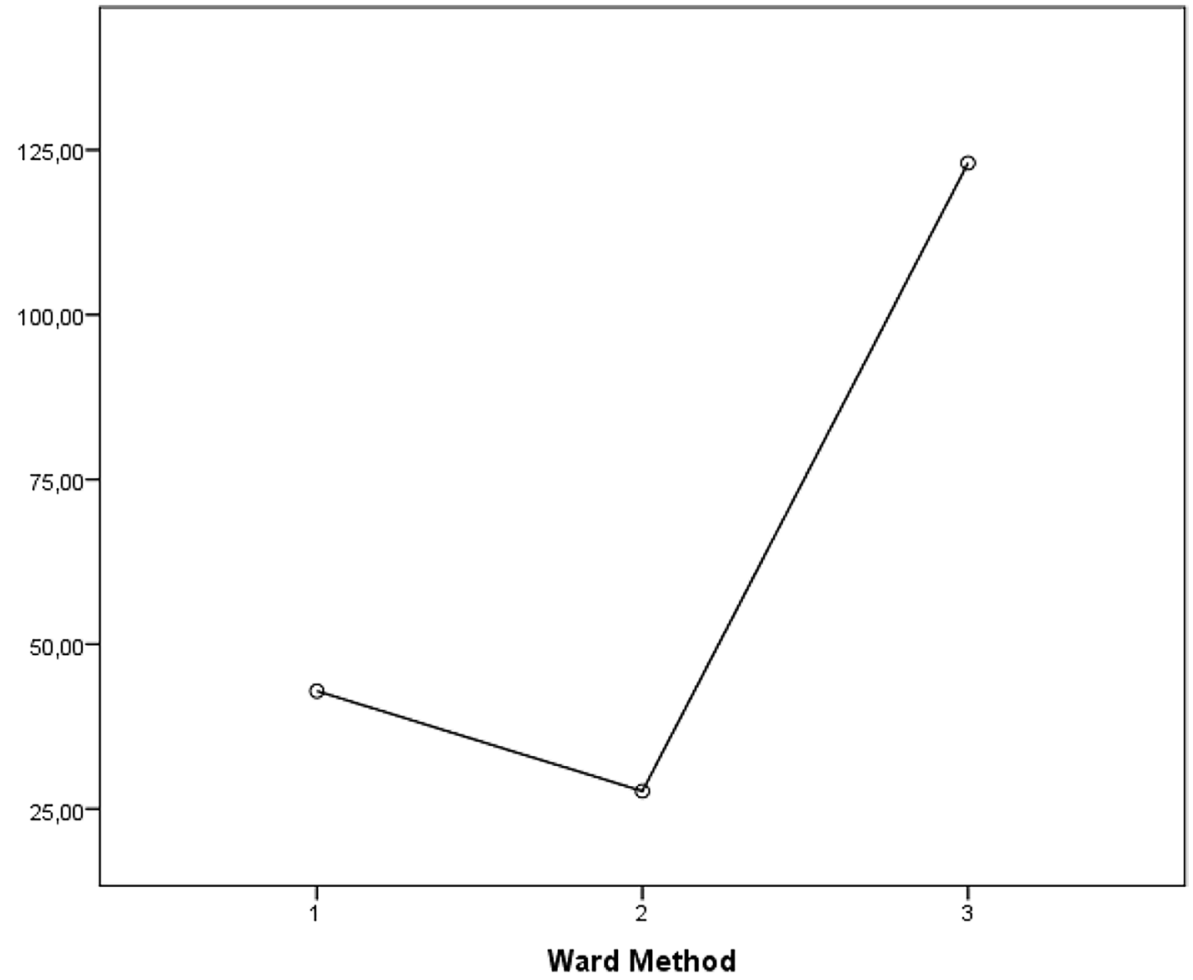

Fig. 7 Average for ROE in year 2 for each cluster

Finally, with regard to the satisfaction of the entrepreneurs with their employees, option 4 "satisfied" obtained $44.4 \%$, followed closely by option 5 "very satisfied" with $42.6 \%$ in this group. This means a very high level of satisfaction (87\%).

\section{Cluster 2}

This group had the poorest results in all the significant financial variables, as shown in Figs. 6, 7 and 8. This cluster's financial results do not denote good business performance in the first years of trading.

As for the behavior of the qualitative variables analyzed, this group had the lowest proportion of companies that received resources from investors, although the figure did not differ substantially from cluster 3 .

This cluster has the most diversified focus with respect to the differentiating factors for success. Of the three groups it is the one that dedicated the smallest percentage to "Innovation" (42.5\%), and its second priority to achieve success was "Personalizing the product or service" (35.5\%). 


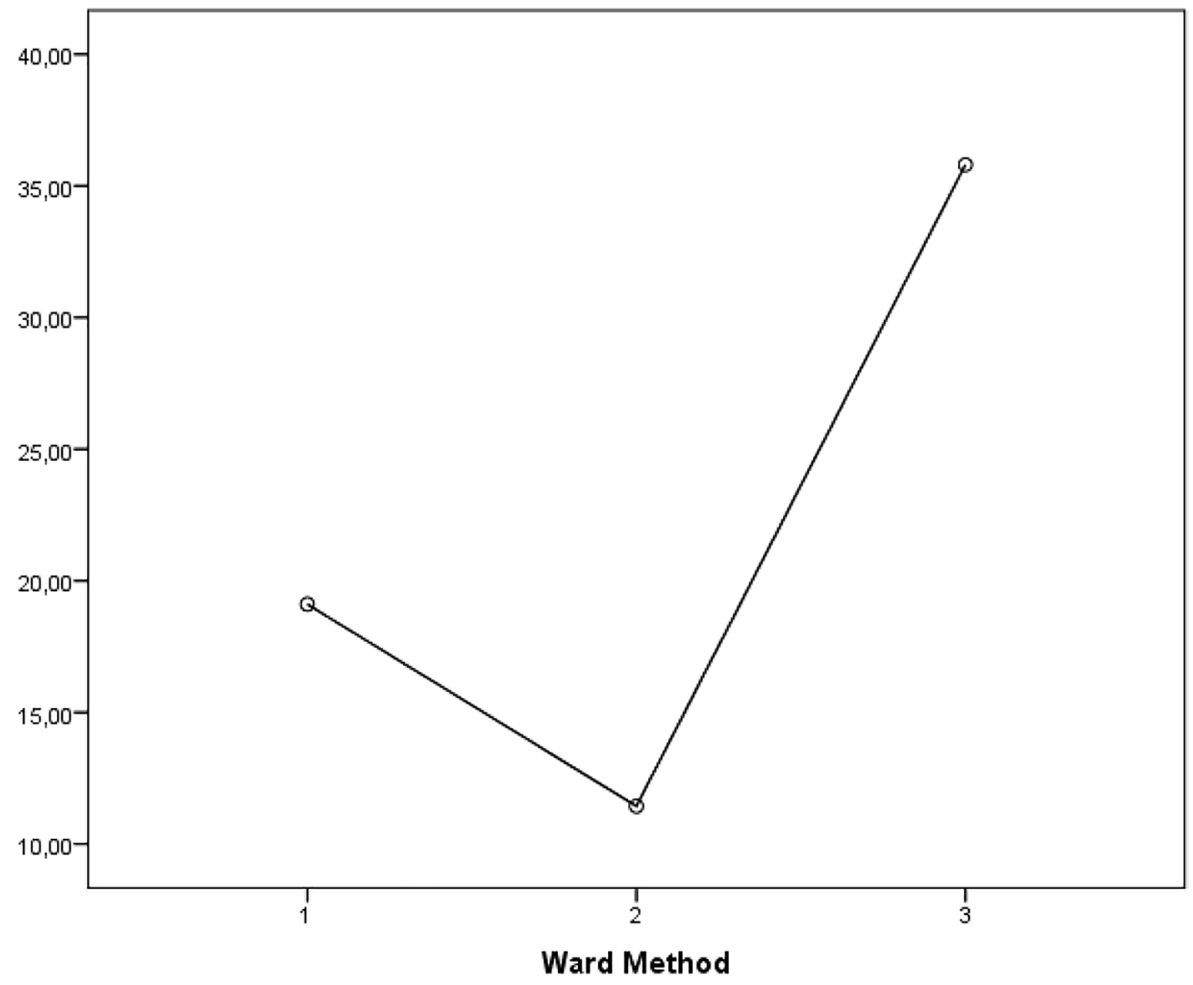

Fig. 8 Average for pre-tax ROA in year 2 for each cluster

Another qualitative variable analyzed was membership of associations. This was the second group population-wise with the highest percentage of company participation in industry associations or being part of a network.

The last variable analyzed was the satisfaction of the entrepreneurs with their employees. The group scored very highly with the option "very satisfied" obtaining $57.5 \%$ of responses, followed by the "satisfied" option with $25 \%$. It was the most satisfied group, although it only differed slightly from cluster 1 in this area.

\section{Cluster 3}

From a financial point of view, this cluster was generally the one that obtained significantly better results than the other two in its second year of business, as shown in Figs. 6, 7 and 8 .

In terms of the behavior of the qualitative variables analyzed, this group had the largest proportion of companies that did not receive investor resources, although there were no significant differences with cluster 2 .

This group was the one that relied most on "innovation" as the differentiating factor for success $(69.2 \%)$. This figure was very different from other factors and from the other clusters. 
Another of the qualitative variables analyzed was membership of networks. Here none of the companies were associated with any business network.

With regard to employers' satisfaction with their employees, although the level of satisfaction was relatively high (69\% were satisfied or very satisfied), this result was significantly below the percentages obtained in the other two clusters.

\section{Discussion}

The results reveal three groups or clusters, which differed both in the composition of their teams and in their business results.

These outcomes show that firstly, according to what was observed in cluster 3 about the "Dispersed Determinants", some of the entrepreneurial partners possess high levels of competencies associated with the Dominance dimension (D), such as result orientation and being resolute and passionate. In addition, they have similar, close-to-average levels of rigor, formality and method, which are Conscientiousness dimension (C) competencies, and high heterogeneity in the Steadiness dimension (S). This combination seems to be related to the capacity to obtain better financial results earlier than other entrepreneurial teams with different profiles. This was also the group of companies that committed most clearly to innovation as a differentiating element. Despite all this, they were the entrepreneurs who were least satisfied on average with their employees, although their constant search for improvement could make them more demanding in this area. Their lack of participation in business networks could also be explained by the high level of Dominance of some of the partners.

Secondly, the results obtained by the "Homogeneously Balanced" group in cluster 2 seem to reveal that a DISC entrepreneurial team profile with very similar member competencies and little diversity in the four dimensions (D, I, S, C) correlated to poorer financial results, at least, in the first years of trading. Besides, it was also the group of companies that was most satisfied with its employees, which could be understood as naivety in light of the circumstances or as a forecast that, in the future, this satisfaction could be reflected in an improvement of their results.

With regard to the "Cautiously Risky" group in cluster 1, it should be pointed out that their great dispersion in the DISC dimensions, especially in the Influence (I) and Conscientiousness $(\mathrm{C})$ dimensions, seems to bring them poor results. A plausible explanation for this is based on the fact that the broad difference in competencies may make teamwork more difficult, since communication and streamlining of work may be hindered by the major differences in what constitutes the particular character of each of the entrepreneurial partners. Again, the degree of satisfaction with employees was high in this cluster.

With regard to the results of the entrepreneurship in terms of attracting resources from external investors, the results of the analysis carried out did not lead to conclusive outcomes. On one hand, it is understood that investors will support the ventures which, in their opinion, offer greater guarantees of success; conversely, the businesses in cluster 3, which obtained the best financial results in the second year, did not receive resources from investors. In future research, it would be worth analyzing 
whether the absence of external investment is explained by the aversion of investors to teams with this composition, their failure to identify the best results, a fast return on investment in the companies in this group that is not sustained over time, or whether these results are precisely better because they did not have to depend on external resources.

A DISC dimension analysis infers that, according to the results found, the set of competencies associated with the Influence dimension (I) did not seem relevant in terms of their effect on the results of the business venture. A detailed analysis of the sample composition reveals a tendency for this statement to be less valid for companies that are dedicated to the purchase and sale of products. This could imply the existence of different ideal entrepreneurial team profiles for each economic sector or industry, an issue that would need to be addressed in future research.

It also seems evident that successful ventures are accompanied by high $\mathrm{D}$ dimension levels, although in a heterogeneous way within the team, with all of them being above average. This means that all the partners were oriented to results and risktaking, but one of them stood out from the rest.

Steadiness $(\mathrm{S})$ is also shown as an attractive dimension to achieve better financial results when combined with a high degree of Dominance that leads to competitive but socially balanced teams. Conversely, it does not appear as an outstanding dimension that has an impact on the results of the venture by itself.

The Conscientiousness dimension (C) shows average levels in the three clusters analyzed, with a slightly greater dispersion in the first one and very high similarity in the third one. The rigor and thoroughness that accompany an individual with a high degree of Conscientiousness can be counterproductive in a venture, which is risky by definition. However, it seems that teams whose members show a certain degree of Conscientiousness and with little dispersion in this dimension can offer important support to attention to detail which leads to good financial results.

\section{Conclusions}

The research question that guides this study sought to connect the combination of entrepreneurial team competencies with the performance of newly created companies. The concept of competency was previously defined to answer the question. The competencies of the entrepreneurs were measured by using DISC (Marston 1928), and business performance was measured by using a tool basically developed by Omerzel and Kušce (2013), Pérez and Canino (2009) and Reijonen and Komppula (2007).

This work provides two important academic and business contributions: one is based on the methodology followed and the second centers on the results obtained in the study, which could pave the way for future research to put forward preliminary hypotheses.

On a methodological level, the DISC model has proved to be useful when analyzing the formation of a team of company founders and studying the impact of the team composition on the results of the new company, which is based largely on how its founding members perform and act. This is because the DISC model 
categorizes four ways of seeing and experiencing the world that translate into four different ways of thinking and acting.

The research results obtained offer some indications of how the composition of entrepreneurial teams can affect the performance of entrepreneurial initiatives in their first years of business. Hopefully, this can provide a tentative basis for suggesting research hypotheses in future studies. A high degree of Dominance at heterogeneous levels among entrepreneurial team members is necessary, accompanied by the Steadiness provided by team-oriented partners, as well as a medium, homogeneous level of Conscientiousness, in order to achieve good financial results in the first two years. The levels of the Influence dimension did not play a significant role. Teams made up of more homogeneous partners obtained the worst financial results. In particular, a homogeneously high degree of competencies associated with authority (D) seems to have negative effects on business performance. Similarly, with high and homogeneous levels of C, entrepreneurs appear to pay much attention to details and quality control, which could lead to low efficiency and paralysis by analysis. The patterns for S and I are not clear and the presence of more or less homogeneous levels of the competencies associated with Steadiness and Influence do not seem to penalize business performance.

Consequently, the results of this research can be useful both for those responsible for programs that support the creation of companies, and for policymakers in the field of entrepreneurship. This study provides guidance on how to increase the effectiveness of the selection process for businesses seeking government support, based on the analysis of entrepreneurial teams. This could facilitate the selection of projects with a higher probability of economic and social return. It also offers guidance on how to improve effectiveness when choosing entrepreneurial teams to initiate training, pre-incubation, incubation, business acceleration and financing processes. Finally, it can facilitate the design of specific programs aimed at enhancing the development of certain competencies and advise on a distribution of roles appropriate to the individual competencies of each entrepreneur.

Despite the rigor all academic work strives to attain, the current research has certain limitations. Firstly, almost all the companies that participated in the study had received support from entrepreneurship programs, so it may not be possible to generalize the results to newly created companies that have not used an entrepreneurship ecosystem.

There is a limitation in having concentrated on analyzing the results in the first two years of business, given that the composition of the sample did not provide the necessary information to analyze whether the three clusters underwent significant changes in business performance in the following years (from years 3 to 10). In addition, taking into account the fact that no significant differences were identified other than in some of the performance measurement variables, it would be advisable in future research to use the model in other samples and populations over a longer number of years.

Another limitation is that this study does not consider any changes that the composition of the team members may have undergone over time and focuses on those that had the same members from the time the company was founded right 
through to the date of the study. Therefore, the results of this research apply to entrepreneurial teams that remained stable during the first years of trading.

Some companies lost values for some financial variables, because of the youth of the company, the lack of records or a cultural aspect of the country in terms of not sharing information related to profitability or liquidity, which limited working with other possible relationships.

Looking to the future, an interesting line of research would be to carry out a longitudinal study, analyzing the relationships studied in different phases of a company's life cycle. In a complementary way, a qualitative study could be carried out to deepen the understanding of what has been studied here and to advance more firmly towards an explanatory piece of research with solidly based hypotheses, based on some particularly significant cases, either because of the success they have obtained or because of the difficulties encountered.

Since this research does not delve deeper into the relationship between the team's competencies and the assignment of roles within the team, future research could analyze whether the assignment of roles is actually consistent with the measured competencies and the most appropriate competencies to perform each role.

Finally, in this research, we removed companies that had closed down at the time of collecting information. These closures could have been partly due to deficiencies in the configuration of the entrepreneurial team's competencies. It would be interesting in the future to investigate the partners' DISC composition in companies that fail in the first years of business.

Now that many countries are deploying strategies to promote entrepreneurship in the framework of the post-COVID economic recovery, it is necessary to have instruments that facilitate decision-making in order to better invest scarce resources that can boost job creation through new businesses.

The results of this research encourage universities and public and private sector organizations and agencies interested in entrepreneurship to consider the personality and competencies of entrepreneurs in their selection, training and development programs. The same DISC model could be used as a measurement tool to develop the competencies of those involved, complementing business plan evaluation or viability by assessing the team that will run the new company.

\section{References}

Aldrich, H. E., \& Auster, E. (1986). Even dwarfs started small: liabilities of size and age and their strategic implications. In B. M. Staw \& L. L. Cummings (Eds.), Research in organizational behaviour (Vol. 8, pp. 165-198). Greenwich: JAI Press.

Altink, W. M., \& Born, M. P. (1993). Prediction of entrepreneurial success: the development of a rating scale for entrepreneurial characteristics. International Journal of Selection and Assessment, 1(2), 95-106.

Backes-Gellner, U., Werner, A., \& Mohnen, A. (2015). Effort provision in entrepreneurial teams: effects of team size, free-riding and peer pressure. Journal of Business Economics, 85(3), 205-230.

Baier-Fuentes, H., Merigó, J. M., Amorós, J. E., \& Gaviria-Marín, M. (2019). International entrepreneurship: a bibliometric overview. International Entrepreneurship and Management Journal, 15(2), 385-429. 
Bayarçelika, E., \& Özşahinb, M. (2014). How entrepreneurial climate effects firm performance? Procedia - Social and Behavioral Sciences, 150, 823-833.

Berglund, H., \& Wennberg, K. (2006). Creativity among entrepreneurship students: comparing engineering and business education. International Journal of Continuing Engineering Education and Life Long Learning, 16(5), 366-379.

Bhagat, S., \& Bolton, B. (2008). Corporate governance and firm performance. Journal of Corporate Finance, 14(3), 257-273.

Brandstätter, H. (1997). Becoming an entrepreneur, a question of personality structure? Journal of Economic Psychology, 18(2-3), 157-177.

Brown, L. \& Caylor, M. (2004). Corporate governance study: the correlation between corporate governance and company performance. Corporate Governance Study, Institutional Shareholder Services.

Brüderl, J., \& Schüssler, R. (1990). Organizational mortality: the liabilities of newness and adolescence. Administrative Science Quarterly, 35, 530-547.

Brüderl, J., Preisendörfer, P., \& Ziegler, R. (1992). Survival chances of newly founded business organizations. American Sociological Review, 57(2), 227-242.

Buyl, T., Boone, C., Hendriks, W., \& Matthyssens, P. (2011). Top management team functional diversity and firm performance: the moderating role of CEO characteristics. Journal of Management Studies, 48(1), 151-177.

Cattell, R. B. (1946). The description and measurement of personality. New York: Harcourt, Brace and World.

Cattell, R. B., Cattell, A. K., \& Cattell, H. E. P. (1993). 16PF fifth edition questionnaire. Champaign: Institute for Personality and Ability Testing.

Chen, H. M., \& Chang, W. Y. (2010). The essence of the competence concept: adopting an organization's sustained competitive advantage viewpoint. Journal of Management \& Organization, 16(5), 677-699.

Chen, T., Tsai, M., \& Chen, Y. (2016). A user's personality prediction approach by mining network interaction behaviors on facebook. Online Information Review, 40(7), 913-937.

Churchill, B. C. (1955). Age and life expectancy of business firms. Survey of Current Business, 35(12), 15-19.

Ciavarella, M., Bucholtz, A., Riordan, C., Gatewood, R., \& Stokes, G. (2004). The big five and venture success: is there a linkage? Journal of Business Venturing, 19(4), 465-483.

CIC. (2015). Centre for internal change. What is DISC. Available at: https://internalchange.com/what-isdisc/. Accessed 28 May 2020.

Clarysse, B., \& Moray, N. (2004). A process study of entrepreneurial team formation: the case of a research-based spin-off. Journal of Business Venturing, 19(1), 55-79.

Congreso de Colombia. (2006). Ley 1014. Fomento a la cultura del emprendimiento. Bogotá: Gaceta Oficial.

Cooney, T. (2005). What is an entrepreneurial team? International Small Business Journal, 23(3), 226-235.

Cooper, A., \& Artz, K. (1995). Determinants of satisfaction for entrepreneurs. Journal of Business Venturing, 10(6), 439-457.

Cuervo, A., Ribeiro, D., \& Roig, S. (2007). Introduction. In A. Cuervo, D. Ribeiro, \& S. Roig (Eds.), Entrepreneurship: concepts, theory and perspective (pp. 1-22). Berlin: Springer Science and Business Media.

Davidsson, P., \& Honig, B. (2003). The role of social and human capital among nascent entrepreneurs. Journal of Business Venturing, 18(3), 301-333.

Delamare, F., \& Winterton, J. (2005). What is competence? Human Resource Development International, $8(1), 27-46$.

Dess, G., \& Davis, P. (1984). Porter's generic strategies as determinants of strategic group membership and performance. Academy of Management Journal, 26(3), 467-488.

Di Zhang, D., \& Bruning, E. (2011). Personal characteristics and strategic orientation: entrepreneurs in Canadian manufacturing companies. International Journal of Entrepreneurial Behaviour y Research, 17(1), 82-103.

Driessen, M.P. \& Zwart, P.S. (1999). The entrepreneur scan: measuring characteristics and traits of entrepreneurs. Working paper, University of Groningen.

Ensley, M., Carland, J., \& Carland, J. (1998). The effect of entrepreneurial team skill heterogeneity and functional diversity on new venture performance. Journal of Business and Entrepreneurship, 10(1), $1-11$. 
Eser, G., \& Özdemirci, A. (2016). Personality characteristics and business philosophy: an entrepreneurship experiment. European Journal of Business and Social Sciences, 4(11), 70-87.

Fernández, R., Revuelto, L., \& Simón, V. (2018). Supervivencia de empresas sociales de nueva creación. Un enfoque basado en el análisis cualitativo comparativo fsQCA. CIRIEC-España, Revista de Economía Pública, Social y Cooperativa, 92, 183-221.

Ferneda, E., do Prado, H., Sobrinho, A., \& Balaniuk, R. (2012). Mining high performance managers based on the results of psychological tests. International Conference on Knowledge-Based and Intelligent Information and Engineering Systems (pp. 78-87). Berlin: Springer.

Forsyth, B., Davis, H., Mitchell, B., \& Fryer, R. (2016). DISCflex leadership/team performance model (DLTPM) (TM). Journal of Organizational Psychology, 16(2), 75-87.

Freeman, J., Carroll, G. R., \& Hannan, M. T. (1983). The liability of newness: age dependence in organizational death rates. American Sociological Review, 48, 692-710.

Gumbus, A., \& Lussier, R. N. (2006). Entrepreneurs use a balanced scorecard to translate strategy into performance measures. Journal of Small Business Management, 44(3), 407-425.

Hafeez, K., \& Essmail, E. (2007). Evaluating organisation core competences and associated personal competencies using analytical hierarchy process. Management Research News, 30(8), 530-547.

Hartle, F. (1995). How to re-engineer your performance management process. London: Kogan Page.

Hoffmann, T. (1998). The meanings of competency. Journal of European Industrial Training, 23(6), 275-285.

INE (2016). Indicadores de demografía empresarial. Press note. https://www.ine.es/prensa/dae_2016. pdf. Accessed 10 June 2020.

Inscape Publishing (1997). The personal development profile. United States of America: Research Report.

Inscape Publishing (2005). Theory DICS everything DISC. Available at: https://humaninsight1.files .wordpress.com/2010/10/everything-disc-teoria-disc.pdf. Accessed 12 June 2020.

John, O. P., Donahue, E. M., \& Kentle, R. L. (1991). The “Big Five” inventory: versions $4 a$ and 54. Berkeley: University of California, Institute of Personality and Social Research.

Kaplan, R., \& Norton, D. (1992). The balanced scorecard. Measures that drive performance. Harvard Business Review, 70(1), 71-79.

Keirsey, D., \& Bates, M. (1984). Please understand me: character and temperament types (5th ed.). Del Mar: Prometheus Nemesis Book.

Khalil, C., \& Khalil, S. (2020). Exploring knowledge management in agile software development organizations. International Entrepreneurship and Management Journal, 16, 555-569.

Kim, L., \& Lim, Y. (1988). Environment, generic strategies, and performance in a rapidly developing country: a taxonomic approach. Academy of Management Journal, 31(4), 802-827.

Kirkley, W. W. (2016). Entrepreneurial behaviour: the role of values. International Journal of Entrepreneurial Behavior \& Research, 22(3), 290-328.

Kollmann, T., Stöckmann, C., Meves, Y., \& Kensbock, J. (2017). When members of entrepreneurial teams differ: linking diversity in individual-level entrepreneurial orientation to team performance. Small Business Economics, 48(4), 843-859.

Levinthal, D. A. (1991). Random walks and organizational mortality. Administrative Science Quarterly, 36, 397-420.

Levy-Leboyer, C. (1997). Gestión de las competencias. Barcelona: Gestión 2000.

Littunen, H. (2000). Entrepreneurship and the characteristics of the entrepreneurial personality. International Journal of Entrepreneurial Behaviour \& Research, 6(6), 295-310.

Lopes, J. N. M., \& Farinha, L. (2018). Measuring the performance of innovation and entrepreneurship networks. Journal of the Knowledge Economy, 9, 402-423.

Marston, W. (1928). Emotions of normal people. New York: Taylor \& Francis Group.

Marulanda, F., Montoya, I., \& Vélez, J. (2014). Aportes teóricos y empíricos al estudio del emprendedor. Cuadernos de Administración, 30(51), 89-99.

McClelland, D. (1976). A guide to job competency assessment. Boston: McBer and Co..

Morris, R. (2011). 2011 High-Impact Entrepreneurship Global Report. Center for High-Impact Entrepreneurship at Endeavor. Global Entrepreneurship Monitor. Available at https://www.gemco nsortium.org/file/open?fileId=47124. Accessed 4 June 2020.

Murphy, G., Trailer, J., \& Hill, R. (1996). Measuring performance in entrepreneurship research. Journal of Business Research, 36(1), 15-23.

Myers, I. B. (1962). The Myers-Briggs Type Indicator manual. Princeton: Educational Testing Service. 
Neumeyer, X., \& Santos, S. C. (2020). A lot of different flowers make a bouquet: the effect of gender composition on technology-based entrepreneurial student teams. International Entrepreneurship and Management Journal, 16(1), 93-114.

Nicholls-Nixon, C., Cooper, A., \& Woo, C. (2000). Strategic experimentation: understanding change and performance in new ventures. Journal of Business Venturing, 15(5-6), 493-452.

Oliva, T., Desarbo, W., Day, D., \& Jedidi, K. (1987). GEMCAT: a general multivariate methodology for estimating catastrophe models. Systems Research and Behavioral Science, 32(2), 121-137.

Omar, R., Lim, K., \& Basiruddin, R. (2014). Board of directors and small medium enterprise's firm growth with firm culture as moderating factor in Malaysia. Procedia-Social and Behavioral Sciences, 164(4), 315-323.

Omerzel, G., \& Kušce, I. (2013). The influence of personal and environmental factors on entrepreneurs' performance. Kybernetes, 42(6), 906-927.

Özer, F., \& Tinaztepeb, C. (2014). Effect of strategic leadership styles on firm performance: a study in a Turkish SME. Procedia - Social and Behavioral Sciences, 150, 778-784.

Pérez, E., \& Canino, R. (2009). The importance of the entrepreneur's perception of success. Review of International Comparative Management, 10(5), 990-1010.

Pérez Fernández, F. (2010). William Moulton Marston: polígrafos, cómics y psicología de la normalidad. Revista de Historia de la Psicología, 31(2-3), 151-166.

Persolog (2007). DISC personality model. Available at: http://www.persolog.net/en/website/navigation/ home/index.htm. Accessed 2 July 2020.

Peterková, J., Wozniaková, Z., \& Skopalová, D. (2015). Performance evaluation of start-ups by using BLUES methodology. In European Conference on Management, Leadership \& Governance (p. 314). Academic Conferences International Limited.

Reijonen, H., \& Komppula, R. (2007). Perception of success and its effect on small firm performance. Journal of Small Business and Enterprise Development, 14(4), 689-701.

RezaeiZadeh, M., Hogan, M., O'Reilly, J., Cunningham, J., \& Murphy, E. (2017). Core entrepreneurial competencies and their interdependencies: insights from a study of Irish and Iranian entrepreneurs, university students and academics. International Entrepreneurship and Management Journal, 13(1), 35-73.

Richard, P., Devinney, T., Yip, G., \& Johnson, G. (2009). Measuring organizational performance: towards methodological best practice. Journal of Management, 35(3), 718-804.

Ripollés, M., \& Blesa, A. (2005). Relación entre la orientación al mercado y la orientación emprendedora su influencia en el rendimiento de la empresa. Revista Europea de Dirección y Economía de la Empresa, 14(3), 165-180.

Rodríguez, J. (2004). La tecnología de evaluación ipsativa y el sistema APP-APT de Thomas International. Revista de Psicología del Trabajo y de las Organizaciones, 20(2), 169-197.

Schjoedt, L., \& Kraus, S. (2009). Entrepreneurial teams: definition and performance factors. Management Research News, 32(6), 513-524.

Stam, W., Arzlanian, S., \& Elfring, T. (2014). Social capital of entrepreneurs and small firm performance: a meta-analysis of contextual and methodological moderators. Journal of Business Venturing, 29(1), $152-173$.

Sugerman, J. (2009). Using the DiSC® model to improve communication effectiveness. Industrial and Commercial Training, 41(3), 151-154.

Tehseen, S., Ahmed, F. U., Qureshi, Z. H., Uddin, M. J., \& Ramayah, T. (2019). Entrepreneurial competencies and SMEs' growth: the mediating role of network competence. Asia-Pacific Journal of Business Administration, 11(1), 2-29.

Ten Haaf, W., Bikker, H., \& Adriaanse, D. (2002). Fundamentals of business engineering and management: a systems approach to people and organizations. Delft: Delft University Press.

Timmons, J. A., Spinelli, S., \& Tan, Y. (2004). New venture creation: entrepreneurship for the 21st century (Vol. 6). New York: McGraw-Hill/Irwin.

Unger, J., Rauch, A., Frese, M., \& Rosenbusch, N. (2011). Human capital and entrepreneurial success: a meta-analytical review. Journal of Business Venturing, 26(3), 341-358.

Venkatraman, N., \& Ramanujam, V. (1986). Measurement of business performance in strategy research: a comparison of approaches. Academy of Management Review, 11(4), 801-814.

Wagner, J. P. (1981). A descriptive, reliability, and validity study of the enneagram personality typology. (Doctoral dissertation, Loyola University of Chicago, 1981). Dissertation abstracts international, 41, 4664.

Weightman, J. (1994). Competencies in action. London: IPD House. 
White, R. (1959). Motivation reconsidered: the concept of competence. Psychological Review, 66(5), 279-333.

Wiklund, J. (2009). Building an integrative model of small business growth. Small Business Economics, 32(4), 351-374.

Zhou, W., Hu, H., \& Zey, M. (2015). Team composition of new venture founding teams: does personality matter? International Journal of Entrepreneurial Behavior and Research, 21(5), 673-689.

Zolin, R., Kuckertz, A., \& Kautonen, T. (2011). Human resource flexibility and strong ties in entrepreneurial teams. Journal of Business Research, 64(10), 1097-1103.

Publisher's note Springer Nature remains neutral with regard to jurisdictional claims in published maps and institutional affiliations.

\section{Authors and Affiliations}

\section{Patricia Fuel $^{1} \cdot$ Manuela Pardo-del-Val $^{2}$ (D) $\cdot$ Lorenzo Revuelto-Taboada $^{2}$}

$\triangle$ Patricia Fuel

pafuel@alumni.uv.es

$\triangle$ Manuela Pardo-del-Val

manoli.pardo@uv.es

$\bowtie \quad$ Lorenzo Revuelto-Taboada

lorenzo.revuelto@uv.es

1 Department of Administrative Sciences, Faculty of Economics, Antioquia University (Colombia), Antioquia, Colombia

2 Department of Business Administration 'Juan José Renau Piqueras', Faculty of Economics, University of Valencia (Spain), Valencia, Spain 